\title{
The Decision Not to Resuscitate Order for Terminally III Pediatric Patients and Ethics as a Predictor from Undergraduate Students' Perspective
}

sawsan abuhammad ( $\sim$ Shabuhammad@just.edu.jo)

Jordan University of Science and Technology https://orcid.org/0000-0001-5817-8950

Suhiab Mufleh

Jordan University of Science and Technology

Karem H Alzoubi

Jordan University of Science and Technology

Research article

Keywords: Do Not Rusticate, Cardiopulmonary Resuscitation, Nursing students, Children

Posted Date: October 28th, 2020

DOI: https://doi.org/10.21203/rs.3.rs-45481/v2

License: (c) (1) This work is licensed under a Creative Commons Attribution 4.0 International License.

Read Full License 


\section{Abstract}

Background: Nurses and Doctor of Pharmacy (PhrmD) must communicate and properly documented the do not resuscitate orders for terminally ill children and their relatives. They also have to offer excellent care including more family support, assisting the child with terminally ill disease in passing on peacefully, and preventing unnecessary cardiopulmonary resuscitation. This research was aimed to survey attitudes of nursing and pharmD undergraduate students about the "do not resuscitate" order for children with terminally ill diseases.

Method: A cross-sectional correlational design was used. More than 400 nursing and pharmD students were recruited in this study. All the participating students were e-mailed information regarding the study, including the web survey link.

Results: Approximately, $60 \%$ of the nursing and phrmD students would disclose the need for the do not resuscitate order for children with terminally ill diseases. The results showed that there was a significant difference in perception toward do not resuscitate order between nursing and pharmD students. The pharmD students had more positive attitude toward do not resuscitate than the nursing students. Demographic variables were not associated with the perception toward do not resuscitate orders.

Conclusion: This study showed that Jordanian nursing and pharmD students are willing to learn more about different aspects of do not resuscitate orders for terminally ill children. Analyzing their responses to many items showed their misconception about do not resuscitate orders for terminally ill children.

\section{Introduction}

Number of children under 20 years comprise $35 \%$ of the whole world population and $40 \%$ of the leastdeveloped nations [1]. The number of children who suffer from terminally ill diseases each year reached as high as 21 million [2]. Because of the low survival rate among terminally ill pediatric patients after the administration of cardiopulmonary resuscitation CPR, a term was found, which is do-not resuscitate (DNR). Although, the survival rate is high after CPR for children who is suffering from terminally ill diseases, all of them died shortly after the CPR [3]. The DNR decisions are made when a child with terminally ill disease refuses resuscitation, poor diagnosis, or if it is evident that the child with terminally ill disease will not survive CPR with better life quality $[4,5]$. The DNR order entails avoiding basic CPR, compressing the chest combined with or without concurrent ventilation, and exceptional CPR that involves defibrillation and medication [3].

According to western regulations, if there is no DNR order for a child with terminally ill disease, CPR must commence within 60 seconds, and defibrillation within three minutes [3,4]. Provisions of western laws dictate that for a child with terminally ill disease, the DNR decision lies with the responsible physician [59]. The physician usually makes his final decision based on the consultation with nurses and PharmDs [10-14]. 
Because nurses and pharmDs spend significant time with the patient [15,16], offering bedside nursing and medical attention within the several hours of their duty shift, they, frequently, start discussing DNR [7, $17,18]$. Besides, nurses and pharmDs have been trained to properly document DNR orders for terminally ill children and to properly inform the child with terminally ill diseases and his relatives offering care, such as more family support, assisting the child with terminally ill disease in passing on peacefully, and preventing unnecessary CPR $[7,15]$. In the Middle East, there is no consensus for nurses and pharmDs about how to practice DNR orders within Since the nursing and pharmD students will be the next generation who will take care of pediatric patients. The attitudes of these students towards DNR decisions are very important. Therefore, this study aimed to survey attitudes of nursing and pharmD undergraduate students about do not resuscitate order for children with terminally ill diseases and whether differences in attitudes existed between nursing and pharmD student.

\section{Method}

This was a descriptive correlational study, utilizing an online survey to assess the attitudes of nursing and pharmD undergraduate students about the do not resuscitate orders for children with terminally ill diseases. The researchers used the $G *$ Power software version 3.1.92 to calculate the required sample size. A significance level of 0.05 , a power of 0.95 , and 11 th variables were used with a medium effect size of 0.15 resulting in a minimum number of subjects being 400 . However, since using electronic surveys have a low response rate, the researcher sent 800 surveys to guarantee enough responses. A total of 800 nursing and pharmD undergraduate students from Jordan University of Science and Technology were contacted, where a flyer was sent to them to participate in the study. Almost 420 survey were returned where 18 of them were excluded for missing data. Thus, the total number of surveys included in the study was 402 consist of two hundred forty-two from nursing and 160 from pharmD. Data collection began in April 2020 and closed in June 2020. The inclusion criteria for participating in the study were nursing or pharmD student enrolled at Jordan University of Science and Technology/ Jordan regardless year or gender. First and second year students were excluded since in these years will not expose to pediatric patients who suffering from terminally ill disease. During the survey filling, the participant was first given brief details regarding the study and its aim. Then, an online consent form was presented, and the participant was instructed to carefully read the informed consent, and click on the agree button at the end of the consent form if he/she was willing to take part in the study. After that, an online survey was disseminated to the participants. Completed questionnaires were automatically saved on Qualtrics software, which is password protected and can only be accessed by the study authors

\section{Instrument}

The web survey included two sections: first, the participants were requested to complete background information that include age, gender, income, living, nationality, year of study, and parent's education. The second part was based on a tool about DNR developed by Dunn [20]. This tool consisted of 25 statements (items), which were scored based on a five-point Likert scale. Likert scale from 1 (not significant/probable) to 5 (very substantial/likely) was used. The total score ranged from 25 to 125 . 
Increased score indicated more positive attitude toward DNR among children with terminally ill disease. This tool was subdivided into three categories: overall perception, expertise, and personal opinions about the issue of DNR. It was acquired from comparable research of nurses 'perception toward DNR order in Saudi Arabia; a Cronbach alpha of 0.82 confirmed the accuracy and suitability of this questionnaire for use in the current study context [21].

\section{Data Analysis}

Statistical package for Social Sciences [SPSS], version 24 was used to conduct data analysis. A survey was excluded if it was missing more than $20 \%$ of the data. In the sample of the current study, the frequencies of missing values across all items were less than $5 \%$. A multivariate diagnostic test was used

to explore the degree of randomness in the identified missing data. The analysis revealed that the missing pattern was random $(p>.05)$. Numbers, percentages, measures of central tendency, and ranges were used to represent descriptive data. Multiple regressions test was conducted to determine the predictors of attitude toward DNR in nursing and pharmD students. The attitude toward DNR total score was entered as an outcome variable, whereas other factors such as age and gender were entered as potential predictors after determining if there is any multicollinearity.

\section{Ethical Consideration}

An ethical approval was given from Jordan University of Science and Technology IRB (2020243). The research was carried out while adhering to the national and international empirical research guidelines and regulations regarding voluntariness and anonymity of the data. Respondents agreed that the findings be published in a scientific journal. The survey did not ask questions that were deemed as sensitive or inappropriate. Since the study instruments may include some items that have the potential of eliciting negative feelings, participants were informed that they could refrain from answering any questions that may elicit distress.

\section{Results}

\section{Demographic Characteristics}

Total of 402 students participated in the study including 242 nursing and 160 pharmD students. Males were 90 (22.4\%) whereas females were 312 (77.6\%). Demographic characteristics of the study participants are shown in Table 1.

\section{Perceptions toward DNR among Nursing and pharmD Students}

Attitude towards DNR among nursing and pharmD students was satisfactory ( $M=69.9, S D=10.3)$. Many students showed agreement to the following statements "DNR orders for terminally ill children help keep patients from suffering unnecessarily $290(69 \%)$ and " The patient or the patient's family must give written permission in orders for the physician to initiate DNR orders for terminally ill children. 267 (66\%). 
Table 2 shows the responses of the study participants regarding their perception toward DNR orders in children with terminally ill diseases.

\section{Differences between nursing and pharmD students regarding DNR}

The T-test was used to compare attitude toward DNR between nursing and pharmD students. For nursing students, the $D N R$ score was $M=84.15, S D=12.8$, whereas for pharmD students, the 'DNR score was $M=85.19, S D=18.6$. Thus, a significant difference in perception toward DNR orders was detected between nursing and pharmD students $(t=-1.3, p=.013)$.

\section{Multiple Regression Analysis}

Multiple regressions were used to predict nursing and pharmD students' attitude about barriers toward participation in research according to demographic variables such as age, gender, income, living place, nationality, year of education and parents' education. Table 3 summarizes the outcomes of the multiple regression tests. All the listed factors were not associated with the perception toward DNR orders ( $p$ value $>0.05)$ except prevention reasons for doing DNR $(t=-2.180, p=.030)$.

\section{Discussion}

This study is the first to investigate the attitude of Jordanian nursing and pharmD students toward DNR orders for terminally ill children. The findings indicate that, despite favorable perspectives on a few elements, Jordanian nursing and pharmD students retain a pessimistic attitude for "DNR orders for terminally ill children" in various important elements on the "attitude on the DNR" survey. In a systematic literature review study, only few studies have investigated the perspectives of students regarding 'DNR orders for terminally ill children or adult. In one study, Al- Mobeireek revealed recommendation of DNR for healthy adult patients were made by only $16 \%$ of Saudi physicians [23]. Another study by lyilikci found that $66 \%$ of anesthesiologists in turkey had ordered written/oral 'DNR orders for terminally ill children [24]. Further research performed by Varon in Singapore observed some misconception regarding 'DNR orders for terminally ill children' among healthcare care providers [25]. These findings show that the implementation of DNR differs based on the Muslim healthcare service providers from one country to another.

Moreover, the response of children show that many students answered "I would like to know more about patient's rights" where their religious beliefs greatly influence their attitude toward DNR $(2.63, S D=1.12)$. Literature search showed no prior studies investigating the perception toward DNR orders for terminally ill children in Jordanian nursing and pharmD students. It is noteworthy that in few studies, medical students and nurses' attitudes toward euthanasia were analyzed [26,27]. Moghadas et al [26] and RastegariNajafabadi et al [27] found that almost 50\% nurses in Iran accepted the practice of euthanasia during surgery. In another observation study, it was found that $50 \%$ of medical scholars in Iran described encouraging opinion toward the use of euthanasia [28]. Previous literature can be compared to the current study since most undergraduate students were from the same religion. Followed by every Islamic sects, 
any kind of euthanasia are not allowed [29]. But "DNR orders for terminally ill children" are not going against the fundamental Islamic regulations [30]. Islam assumes life as sacred [30] while comprehends death to be unavoidable aspect of life [20]. Muslims acknowledges death is authorized by God [31]. Thus, treatments are not implied when they just prolong the sufferings of terminal sickness [30]. Removing lifeenduring remedies in that situation may appear to allow death to make its natural approach [31]. Hence, the pessimistic impression of Jordanian nursing and pharmD students over "DNR orders for terminally ill children" is not explained with their religious principles and affiliations. It is noteworthy that undergraduate students are showing favorable opinion to additionally understand distinct characteristics of DNR orders for terminally ill children. On the other hand, many undergraduate students revealed that their strict religious convictions greatly impact their attitude toward DNR. One main explanation of the pessimistic approach on "DNR orders for terminally ill children" might arise from absence of deep understanding over DNR orders for terminally ill children. The same way earlier studies indicated that nursing and pharmD students have limited information about many ethical dilemmas [32]. Though many differences in point of view is observed between Muslims, the perspectives on death remains the same [30].

The multiple regression analysis was conducted in the current study to understand the impact of demographic characteristics nursing and pharmD students on their perceptions toward DNR orders for terminally ill children. It was shown that these characteristics were not linked substantially to the nursing and pharmD students ' attitudes toward the DNR issue. However, this finding contrasts with a prior study, which revealed that religious convictions significantly affect more than $70 \%$ of the undergraduate students concerning their opinion of DNR orders for terminally ill children [34]. Nevertheless, the finding of the current study corresponds with the outcomes of several other studies in this area [34-36]. In many ways, spiritual and religious problem is generally awakened or worsened for dying patients [34]. Many researchers have examined the influence of religion, ethics, and culture to ensure an appropriate end to life $[35,36]$. Furthermore, consideration of the impact of culture and faith on the attitude and posture of future healthcare providers should be an essential part of any strategy to be developed to aid patients when it's a life and death situation [33]. According to previous studies, ethical reasoning, and justification of $D N R$ order in critically ill patients with prolonged suffering should be based on the clinical reality, patient preferences, quality-of-life considerations, and the likelihood of surviving cardiopulmonary resuscitation (CPR). Healthcare providers use their knowledge and skills to make reasonable actions to optimize patients' health outcomes in accordance with professional judgment. The DNR can be ethically acceptable, especially when death is welcome by the patient as a natural process of life. Since healthcare providers are portioned to communicate with patients and families about end-of-life care and the hard decisions to make with a great focus on patients' preferences and autonomy, they may be aware of the emotional pressure they may exert on patients and family members when assisting with communication about DNR orders [38]. Without prior singed DNR orders, the role of physicians can be more complex. One of the big ethical challenges of end-of-life care is withholding and withdrawing care that is unlikely to provide physiological benefits for patients. Thus, standards for excellent care should be established to respect the autonomy of patients at the end of life, which in turn can help physicians make effective 
decision-making without being hesitant from providing care for desperately ill patients [38,39]. Based on current results, gender did not significantly influence the DNR decision. However, there is a need for more research to substantiate this claim.

\section{Implications for practice}

The outcomes of this research have suggestions for real life exercises and could be generalized to all students in developing countries with similar situations. Results showed that Jordanian nursing and pharmD students had a negative attitude toward many key aspects of DNR orders for terminally ill children. This means that Jordanian nursing and pharmD students could be opposing any legalization of DNR orders for terminally ill children. Besides, this study shows that Jordanian nursing and pharmD students were willing to learn more about different aspects of DNR orders for terminally ill children. By analyzing their responses to multiple items, misconception about DNR orders for terminally ill children was apparent. Therefore, it is important to provide education programs about DNR for those students during their study and to integrate DNR within courses in the undergraduate curricula of in nursing and PharmD. According to the study outcome, the attitude of Jordanian nursing and pharmD students about DNR orders for terminally ill children may change by such education.

\section{Conclusion}

A non-Western nation adds to knowledge as it extends our understanding of this subject in another context. The results showed that there was a significant difference in perception toward do not resuscitate order between nursing and pharmD students. The pharmD students had more positive attitude toward do not resuscitate than the nursing students. Demographic variables were not associated with the perception toward do not resuscitate orders. This study shows that Jordanian nursing and pharmD students are willing to learn more about different aspects of DNR orders for terminally ill children and analyzing their responses to many items showed their misconception about DNR orders for terminally ill children.

\section{Declarations}

Ethics approval and consent to participate: This research got an Approval from Jordan University of Science and Technology IRB(\#20202343). Consent form was signed from all the participants.

Consent to publish: We gave the right to BMC Palliative Care to publish

Availability of data and materials: data will be sent upon request

Competing interests: no conflict of interest for any author in this paper

Funding Section: This project was carried out as part of "The Research Ethics Education Program in Jordan" and has been supported by NIH grant number (1R25TW010026-01). The funder support data collection and fees for publication.

All authors have read and approved the manuscript" and ensure that this is the case. 
Acknowledgment: DNR Questionnaire was approved to use from Dunn (2000).

The instrument was developed by Dr Dunn and permission was given to use it.

\section{Authors' Contributions}

SA and SM: Conceptualization; Data curation; Formal analysis; Funding acquisition; Investigation; Methodology; Project administration; Resources; Software; Supervision; Validation; Visualization; Roles/Writing - original draft; Writing - review \& editing.

KA: Data curation; Formal analysis; Funding acquisition; Investigation; Methodology; Project administration; Resources; Supervision; Validation; Visualization; Roles/Writing - original draft; Writing review \& editing

\section{Abbreviations}

PPC= Pediatric Palliative Care

PCQN= Palliative Care Nursing Questionnaire

DNR: Do not resuscitate orders

PharmD = Doctor of Pharmacy

\section{References}

1. World population data sheet. Washington DC: Population Reference Bureau; 2014 (http://www. prb.org/pdf14/2014-world-population-data-sheet_eng.pdf, accessed 17 March 2018).

2. Connor SR, Downing J, Marston J. Estimating the global need for palliative care for children: a crosssectional analysis. J Pain Symptom Manage. 2017;53(2):171-7..

3. WHO. WHOQOL: Measuring Quality of Life. 2018 [cited 15 August 2018]. In Health statistics and information systems [Internet]. Geneva: WHO. Available from: http://www.who.int/healthinfo/survey/whoqol-qualityoflife/en/

3. .Burns JP, Truog RD. The DNR Order after 40 Years. N Engl J Med. 2016 Aug 11. pmid:27509098

4. Pettersson M, Hedstrom M, Hoglund AT. Striving for good nursing care: Nurses' experiences of do not resuscitate orders within oncology and hematology care. Nurs Ethics. 2014 Jun 9. pmid:24913543

5. Silen M, Svantesson M, Ahlstrom G. Nurses' conceptions of decision making concerning lifesustaining treatment. Nurs Ethics. 2008 Feb 15. pmid:18272607

6. Clements M, Fuld J, Fritz Z. Documentation of resuscitation decision-making: a survey of practice in the United Kingdom. Resuscitation. 2014 Feb 25. pmid:24560825 
7. Adhikari S, Rijal S. Attitude of doctors working in a tertiary hospital towards Do-not-resuscitate decisions. Journal of General Practice and Emergency Medicine of Nepal. 2019 Dec 31;6(8):13-6.

8. Naghshbandi S, Salmasi S, Parsian Z, Rahmani F. Attitude of nurses in intensive care units towards Do Not Resuscitate order. Journal of Research in Clinical Medicine. 2019 Dec 20;7(4):122-8.

9. Shayestefar S, Mardani-Hamooleh M, Kouhnavard M, Kadivar M. Ethical challenges in pediatrics from the viewpoints of Iranian pediatric residents. Journal of Comprehensive Pediatrics. 2018;9(1).

10. Schwartz JA. Innovation in pediatric surgery: the surgical innovation continuum and the ETHICAL model. J Pediatr Surg. 2014;49(4):639-45. doi: 10.1016/j.jpedsurg.2013.12.016. [PubMed: 24726128].

11. Asemani O, Parsaei H. Decisionmaking on the prolongation of the life of severely diseased newborns: reinspection of criteria. Iranian J Med Ethics Hist Med. 2012;5(5):36-52.

12. Salem A, Salem AF. Breaking bad news: current prospective and practical guideline for Muslim countries. J Cancer Educ. 2013;28(4):790-4. doi: 10.1007/s13187-013-0523-8. [PubMed: 2387295

13. Levin T, Li Y, Weiner J, Lewis F, Bartell A, Piercy J. How do-not-resuscitate orders are utilized in cancer patients: Timing relative to death and communicating-training implications. Palliat Support Care. 2008 Dec. pmid: 19006588

14. Duplan KL, Pirret AM. Documentation of cardiopulmonary resuscitation decisions in a New Zealand hospital: A prospective observational study. Intensive Crit Care Nurs. 2016 Dec. pmid:27575617

15. Peimani M, Zahedi F, Larijani B. Do not resuscitate order across societies and the necessity of a national ethical guideline. Iranian J Med Ethics Hist Med. 2012;5(5):19-35. 30

16. Izadikhah A, Changiz YN, Mirshahjafarey I. Developing codes of ethics for clinical medicine educators. Iranian J Med Ethics Hist Med. 2013;6(1):37-52.

17. Jensen $\mathrm{HI}$, Ammentorp J, Johannessen $\mathrm{H}$, Ording H. Challenges in end-of-life decisions in the intensive care unit: an ethical perspective. J Bioeth Inq. 2013 Mar. pmid:23299401

18. Mockford C, Fritz Z, George R, Court R, Grove A, Clarke B, et al. Do not attempt cardiopulmonary resuscitation (DNACPR) orders: a systematic review of the barriers and facilitators of decisionmaking and implementation. Resuscitation. 2015 Mar. pmid:25433293

19. Pfeil TA, Laryionava K, Reiter-Theil S, Hiddemann W, Winkler EC. What keeps oncologists from addressing palliative care early on with incurable cancer Health, 2016; 4(2): 55-59.

20. Dunn MC. MS Dissertation.Long Beach: Department of Social Work, California State University; 2000. Attitudes of medical personnel toward do-not-resuscitate orders

21. Fallahi M, Banaderakhshan H, Abdi A, Borhani F, Kaviannezhad R, Karimpour HA. The Iranian physicians attitude toward the do not resuscitate order. Journal of multidisciplinary healthcare. 2016;9:279.

22. Mahon MM, McAuley WJ. Oncology nurses' personal understandings about palliative care. Oncol Nurs Forum. 2010 May. pmid:20439199 
23. Iyilikci L, Erbayraktar S, Gökmen N, Ellidokuz H, Kara H, Günerli A. Practices of anaesthesiologists with regard to withholding and withdrawal of life support from the critically ill in Turkey. Acta Anaesthesiol Scand. 2004;48:457-62.

24. Al-Mobeireek AF. Physicians' attitudes towards 'do-not-resuscitate'orders for the elderly: A survey in Saudi Arabia. Arch Gerontol Geriat. 2000;30:151-60.

25. Varon J, Bisbal Z, Vargas B, Fromm RE, Jr, Tai DY. Cardiopulmonary resuscitation preferences among health professionals in Singapore. Crit Care Shock. 2004;7:219-25.

26. Moghadas T, Momeni M, Baghaeei M, Ahmadi S. Intensive care unit of nurses' attitudes toward euthanasia. Iranian J Med Ethics Hist Med. 2012;5:80-86.

27. Rastegari-Najafabadi H, Sedaghat M, Saeedi Tehrani S, Aramesh K. Nurses' attitudes Tehran of Medical University hospitals towards euthanasia. Iranian J Med Ethics Hist Med. 2010;3:37-44.

28. Tavosian A, Sedaghat M, Aramesh K. Attitudes of interns Tehran University of medical sciences towards euthanasia. Iranian J Med Ethics Hist Med. 2009;3:43-51.

29. Takrouri M, Halwani T. An Islamic medical and legal prospective of do not resuscitate order in critical care medicine. Internet J Health. 2008;7:12-16

30. Sarhill N, LeGrand S, Islambouli R, Davis MP, Walsh D. The terminally ill Muslim: Death and dying from the Muslim perspective. Am J Hosp Palliat Care. 2001;18:251-5. .

31. Zahedi F, Larijani B, Tavakoly Bazzaz J. End of life ethical Issues and Islamic views. Iran J Allergy Asthma Immunol. 2007;6:5-15.

32. Zahedi F, Larijani B. Cancer ethics from the Islamic point of view. Iran J Allergy Asthma Immunol. 2007;6:17-24.

33. Zarghami M, Valaie N, Sartakhti AA, Mehraban M, Mahmoudi R, Moonesi FS. Attitudes of iranian interns and residents towards euthanasia. World Appl Sci J. 2010;8:486-9.

34. Jung JY, Shin SY. Awareness and Ethical Attitudes about DNR of Emergency Department Students: Differences in Recognition According to Bioethics Education.

35. Emami-Razavi S, Ghajarzadeh M, Oryani S, Askari F, Jalilian R, Azizi S. Perspectives of Iranian medical nurses about do-not-resuscitate (DNR) orders. Academic Journal of Surgery. 2014;1(3-4):4951.

36. Hileli I, Weyl Ben Arush M, Hakim F, Postovsky S. Association between religious and socio-economic background of parents of children with solid tumors and DNR orders. Pediatric blood \& cancer. 2014 Feb;61(2):265-8.

37. American Nurses Association. Nurses' roles and responsibilities in providing care and support at the end of life. Revised position statement. 2016 , 3(2)

38. Luce,. M., White,. B. The pressure to withhold or withdraw life-sustaining therapy from critically ill patients in the United States. American journal of respiratory and critical care medicine, 175(11), 1104-1108. 


\section{Tables}

Page $11 / 17$ 
Table 1: Frequency Distribution of Socio-demographic Characteristics of Undergraduate Students $(n=402)$

\begin{tabular}{|c|c|}
\hline Variable & Frequency (\%) \\
\hline \multicolumn{2}{|l|}{ Gender } \\
\hline Male & $90(22.4)$ \\
\hline Female & $312(77.6)$ \\
\hline \multicolumn{2}{|l|}{ Nationality } \\
\hline Jordanian & $325(80.8)$ \\
\hline other & $77(19.2)$ \\
\hline Age & $\mathrm{M}=20.3(\mathrm{SD}=2.6)$ \\
\hline \multicolumn{2}{|l|}{ Mother education } \\
\hline Primary or secondary & $125(31.1)$ \\
\hline Diploma & $55(13.7)$ \\
\hline Bachelor & $143(35.6)$ \\
\hline Graduate & $79(19.7)$ \\
\hline \multicolumn{2}{|l|}{ Father education } \\
\hline Primary or secondary & $118(29.4)$ \\
\hline Diploma & $101(25.1)$ \\
\hline Bachelor & $134(33.3)$ \\
\hline Graduate & $49(12.2$ \\
\hline \multicolumn{2}{|l|}{ College level } \\
\hline Freshmen (first year) & $23(5.7)$ \\
\hline Sophomore (second year) & $30(7.5)$ \\
\hline Junior (third year) & $78(19.4)$ \\
\hline Senior (fourth year) & $130(32.3)$ \\
\hline Senior (fifth year) & $105(26.1)$ \\
\hline Senior (sixth year) & $36(9.0)$ \\
\hline \multicolumn{2}{|l|}{ Income } \\
\hline Less than 400 & $47(11.7)$ \\
\hline 400 to 600 & $86(21.4)$ \\
\hline 600 to 800 & $61(15.2)$ \\
\hline 800 to 1000 & $85(21.1)$ \\
\hline More than 1000 & $123(30.6)$ \\
\hline \multicolumn{2}{|l|}{ Speciality area } \\
\hline Nursing & $242(16.4)$ \\
\hline PharmD & $160(42.9)$ \\
\hline \multicolumn{2}{|l|}{ Area of living } \\
\hline City & $261(64.9)$ \\
\hline Village & $141(35.1)$ \\
\hline \multicolumn{2}{|l|}{ Prior Experience with DNR } \\
\hline No & $150(37.3)$ \\
\hline Yes & $252(62.7)$ \\
\hline \multicolumn{2}{|l|}{ DNR } \\
\hline No & $350(87.1)$ \\
\hline Yes & $52(12.9)$ \\
\hline \multicolumn{2}{|l|}{ Reasons for Preventing DNR } \\
\hline Religious reasons & $78(19.4)$ \\
\hline Social reasons & $78(19.4)$ \\
\hline Scientific & $50(12.4$ \\
\hline
\end{tabular}


.able (2): Responses to DNR items for nursing and pharmD students $(\mathrm{n}=402)$ 


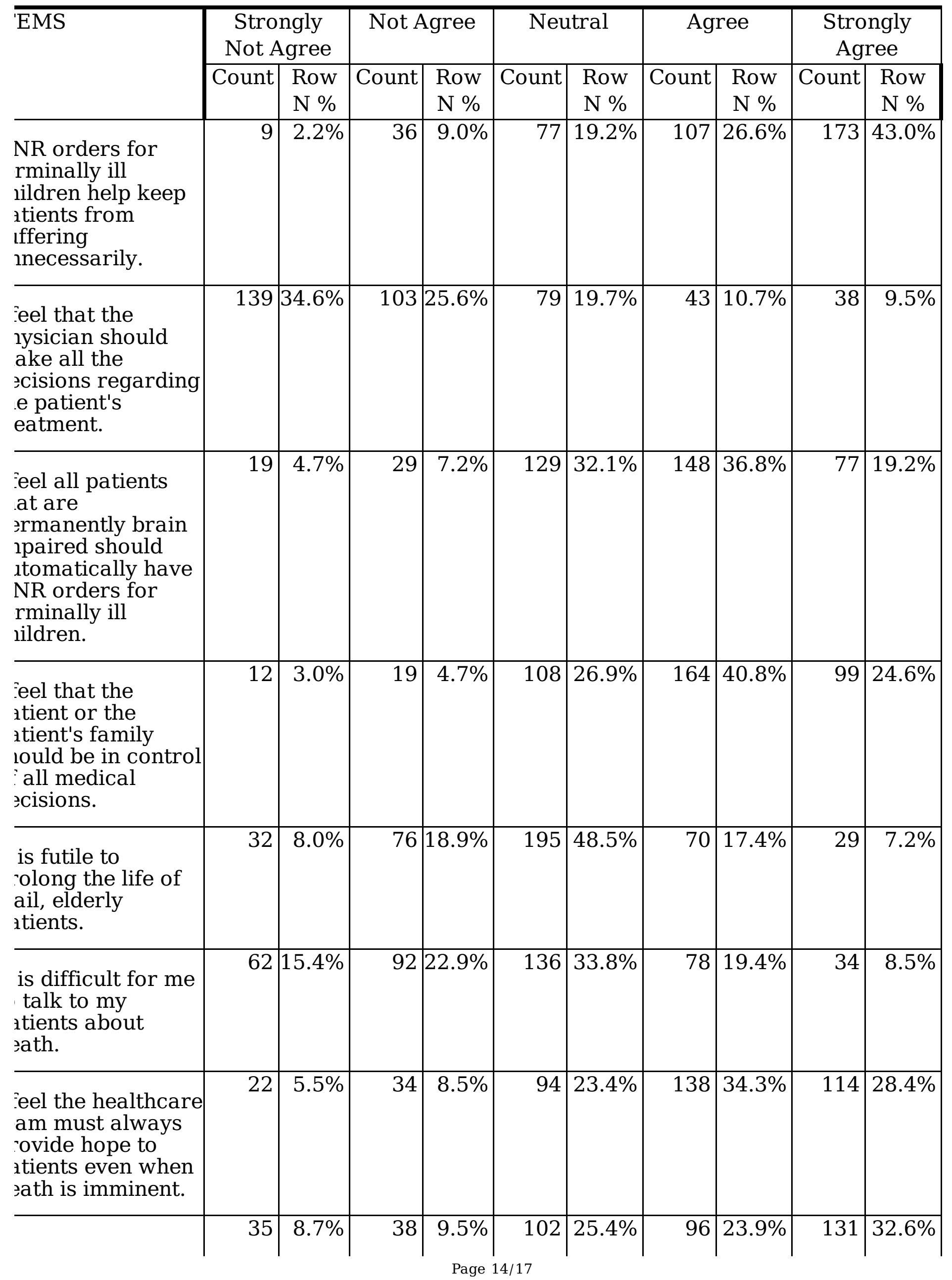


fe-prolonging ruipment can idermine the ttural process of zath.

le monetary ctor of keeping rminally ill t tients alive is fficult to justify.

$m$ afraid the mily will file a wsuit if their mily member is t resuscitated.

Nish I had a better iderstanding of e legal imifications of NR.

wish I knew more sout advance care rectives.

would like to low more about ttient's rights.

my mother was Id-stage rminally ill, I ould not want NR orders for rminally ill iildren written.

y religious beliefs eatly influence $\mathrm{y}$ view of DNR.

y cultural ickground makes difficult for me to sal with the DNR sue.

re patient or the

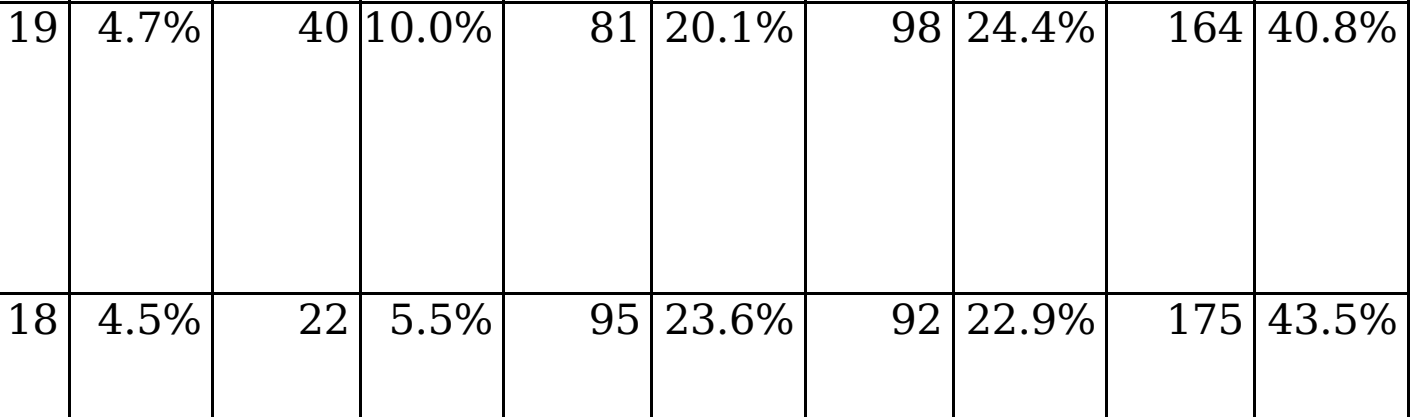


ıtient's family ust give written ormission in ders for the uysician to initiate NR orders for rminally ill sildren.

:eel pressure from e hospital ilization review to ish for DNR ders for rminally ill iildren.

Eeel I must inform to my sers wishes :garding DNR ders for rminally ill iildren.

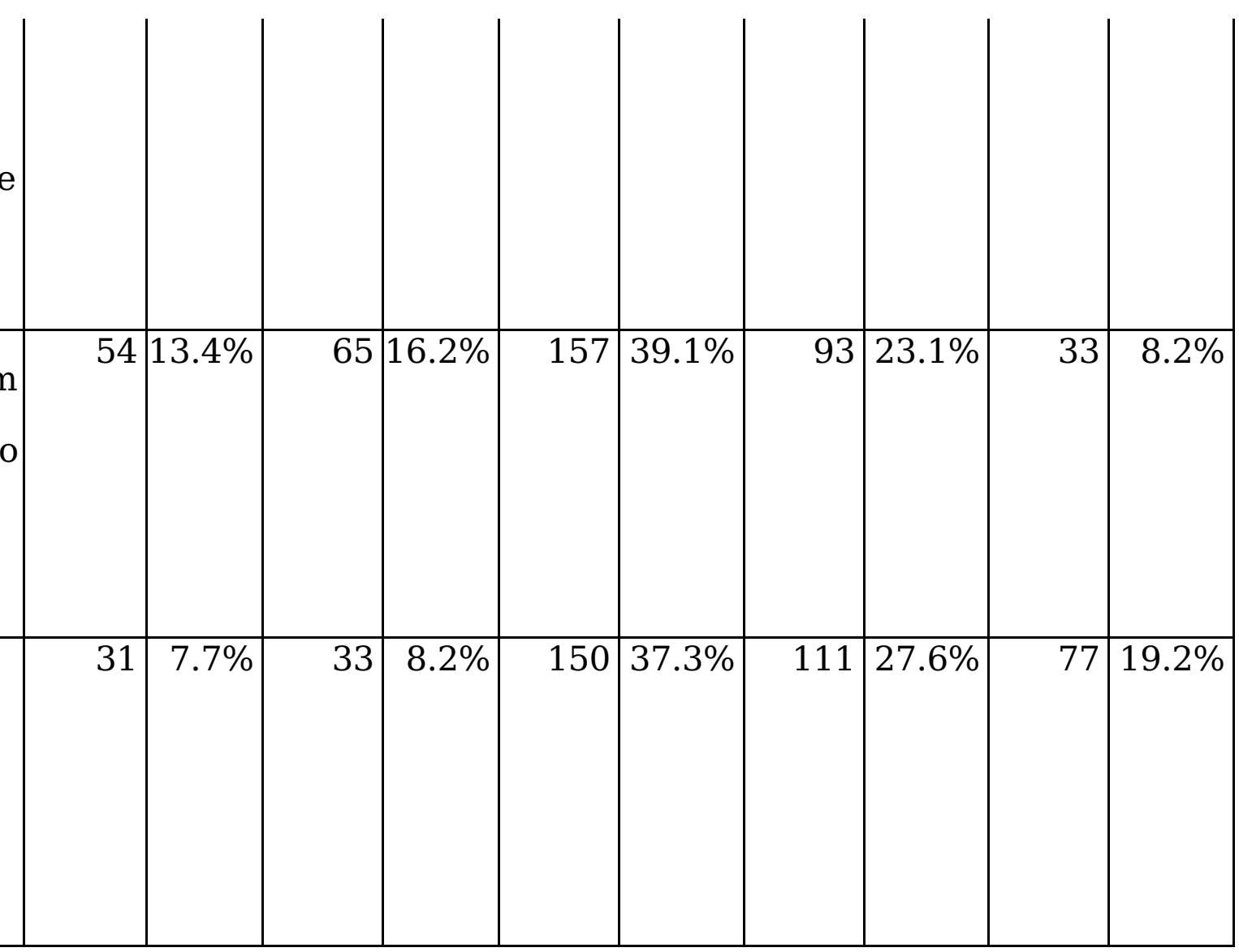

Table 3: Multiple Regression for predictors of DNR of terminally ill children

\begin{tabular}{|c|c|c|c|c|c|c|}
\hline \multirow{2}{*}{\multicolumn{2}{|c|}{ Model }} & \multicolumn{2}{|c|}{$\begin{array}{l}\text { Unstandardized } \\
\text { Coefficients }\end{array}$} & $\begin{array}{l}\text { Standardized } \\
\text { Coefficients }\end{array}$ & \multirow[t]{2}{*}{$\mathrm{t}$} & \multirow[t]{2}{*}{ Sig. } \\
\hline & & B & $\begin{array}{l}\text { Std. } \\
\text { Error }\end{array}$ & Beta & & \\
\hline \multirow[t]{14}{*}{1} & (Constant) & 93.260 & 10.232 & & 9.114 & .000 \\
\hline & age & -.539 & 393 & -.093 & -1.372 & .171 \\
\hline & gender & -.364 & 1.573 & -.013 & -.231 & .817 \\
\hline & Research & .511 & 2.280 & .013 & .224 & .823 \\
\hline & Hear about DNR & .082 & 1.440 & .003 & .057 & .955 \\
\hline & Discuss DNR & -3.477 & 2.025 & -.101 & -1.718 & .087 \\
\hline & Prevent reasons & -1.197 & .549 & -.124 & -2.180 & .030 \\
\hline & \begin{tabular}{|l|l|l|l|l|l|} 
Ethics & -1.197 & .549 & -.124 & -2.180 & .030 \\
\end{tabular} & -.197 & .59 & -.014 & -.180 & .080 \\
\hline & Income & .203 & .506 & .024 & .401 & .689 \\
\hline & living & 2.614 & 1.418 & .107 & 1.844 & .066 \\
\hline & Nationality & -.170 & 1.693 & -.006 & -.100 & .920 \\
\hline & year & 1.098 & .699 & .107 & 1.570 & .117 \\
\hline & Father education & .114 & .725 & .010 & .157 & .875 \\
\hline & Mother education & .811 & .680 & .078 & 1.193 & .234 \\
\hline
\end{tabular}

a. Dependent Variable: Attitude toward DNR 
Page 17/17 